\title{
PARA SABER MAIS ALÉM...
}

Gildenir Carolino Santos ${ }^{1}$

${ }^{1}$ Universidade Estadual de Campinas. Sistema de Bibliotecas

\section{Correspondência}

${ }^{1}$ Gildenir Carolino Santos

Universidade Estadual de Campinas

Sistema de Bibliotecas

Campinas, SP.

E-mail: rdbci@unicamp.br

ORCID: http://orcid.org/0000-0002-4375-6815

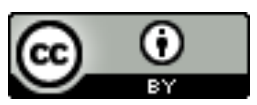

JITA: H. Information sources, supports, channels. 


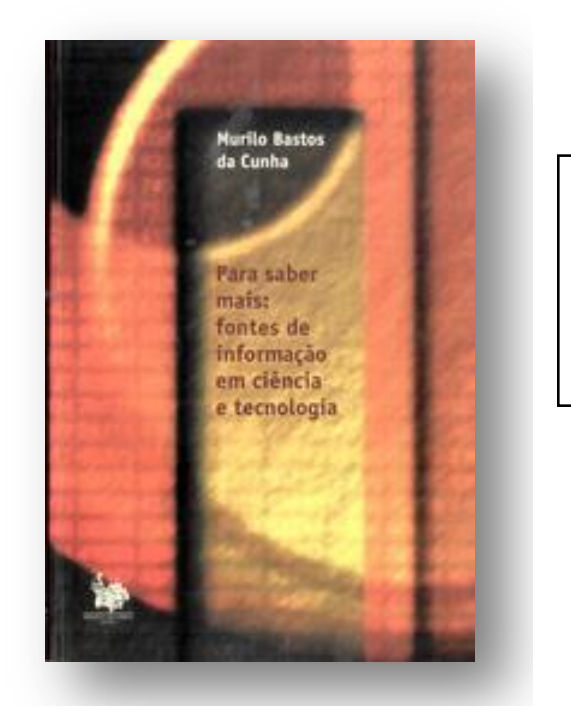

CUNHA, Murilo Bastos da. Para saber mais: fontes de informação em ciência e tecnologia. 2. ed. Brasília, DF: Briquet de Lemos, 2016. 235p. ISBN 858563717X (Arquivo digital).

Murilo Bastos da Cunha é professor titular da Faculdade de Ciências da Informação da Universidade de Brasília. É bacharel em Biblioteconomia pela Universidade de Brasília com especialização em Biblioteconomia em Minas e Energia, e mestre em Administração de Bibliotecas pela Universidade Federal de Minas Gerais. Doutor em Ciência da Informação pela University of Michigan, onde fez também seu pós-doutorado. Foi presidente da Associação dos Bibliotecários do Distrito Federal e do Conselho Federal de Biblioteconomia. Entre as atividades exercidas na UnB estão as de diretor da Faculdade de Estudos Sociais Aplicados, chefe do Departamento de Biblioteconomia e Documentação e diretor da Biblioteca Central. Tem vários trabalhos publicados em diversos periódicos e vários livros.

O professor Murilo Bastos da Cunha é uma grande pessoa, pois o conheço há mais de 20 anos, e geralmente quando nos encontramos nos eventos da nossa área, trocamos "figurinhas" e nos atualizamos com as informações que um passa ao outro. O professor Murilo, como geralmente todos o chamam é um grande colaborador e incentivador da área, pois muita coisa já fez para a Biblioteconomia e continua a fazer, além de gerar novos conhecimentos com as orientações de dissertações e teses, também na área da aprendizagem leciona até o momento na UnB, em Brasília.

Vale lembrar que já foi feita uma resenha da primeira edição dessa obra pelo também bibliotecário e docente na Universidade Federal de Minas Gerais, professor Paulo da Terra Caldeira no periódico, Perspectivas em Ciência da Informação, v.6, n.2, 2001.

Publicada e distribuída exclusivamente no formato eletrônico pela editora Briquet de Lemos em 2016, a segunda edição do livro "Para saber mais: fontes de informação em ciência e tecnologia", contem 235 páginas, 57 páginas a mais do que a primeira edição. Foi editada no idioma português e o custo do arquivo da obra completa é no valor de R $\$ 10,00$, constituindo assim, um riquíssimo conteúdo para a pesquisa. No comentário pessoal com o autor, por meio de e-mail, ele mesmo comenta que o livro "é tão barato que não compensa

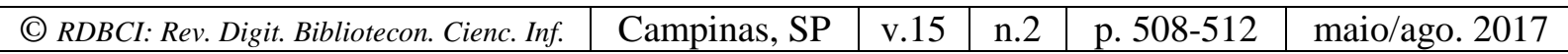


piratear...". No meu ponto de vista considero esse trabalho feito pelo bibliotecário Murilo Bastos da Cunha, uma obra prima de vanguarda para a nossa área (Biblioteconomia e Ciência da Informação), assim para as áreas correlatas afins, em que os pesquisadores buscam encontrar fontes rápidas e atualizadas para o cotidiano de suas pesquisas. Vale lembrar que o arquivo da segunda edição possui traços de marcação de editoração, mas nada que impeça a leitura do mesmo.

Ainda assim, o próprio autor disponibilizou pela rede colaborativa "Academia.edu", a versão da primeira edição do livro em PDF com 168 páginas, mas que não possui a atualização ampla encontrada nessa segunda edição.

Desde há muito tempo, não temos uma obra tão qualificada e primorosa como essa na área da Biblioteconomia brasileira. É uma excelente obra de referência para as rotinas do Bibliotecário de Referência, ou melhor, ainda, pode ser considerada uma bíblia para a pesquisa brasileira, pois ajudará muito aos pesquisadores e beneficiará aos alunos da área da Biblioteconomia e Ciência da Informação que estudam para ser um bom profissional da informação, especificamente na área da Referência, irá reconhecer nessa obra o recurso para mapear todos os tipos de fontes de informação que desejam repassar aos seus usuários nos diversos campos do conhecimento, especificamente no campo da Ciência e Tecnologia.

Nos dias atuais, em que o foco é trabalhar com a informação eletrônica, esse arquivo com a versão disponibilizada da obra completa poderá ser levado para qualquer canto do planeta, por meio de notebooks, tablets, pen drives e depositado nas nuvens que todo indivíduo possui uma conta no Google Drive, OneDrive, Dropbox, etc.

A primeira edição, lançada em 2001, estava esgotada desde 2010. Assim, o autor trabalhou arduamente para atualizar o seu conteúdo. Nessa obra foi incluído o máximo de fontes de informação hospedadas na web.

Também foram incluídos, entre outros, temas novos como gerenciadores de bibliografias, agregadores de periódicos, livro eletrônico, ética na pesquisa e redes sociais.

Conforme explica o autor:

Esta obra adota o arranjo da tipologia proposta por Grogan. Seu objetivo principal é servir de guia para estudantes universitários, professores e pesquisadores das diversas áreas da ciência e tecnologia, para se orientarem na vasta literatura especializada. As ciências biomédicas não foram incluídas. Procurou-se incluir, de forma seletiva, as principais fontes - sejam documentos impressos, documentos eletrônicos, instituições e sítios da internet. Por conseguinte, não houve intenção de fazer um estudo exaustivo. $\mathrm{O}$ escopo foi o de analisar aquelas fontes gerais que pudessem ser úteis para um mais amplo espectro de usuários brasileiros. Não se

${ }^{1}$ Primeira edição disponível em:

https://www.academia.edu/6893434/Para_saber_mais_fontes_de_informa\%C3\%A7\%C3\%A30_em_ci\%C3\%A Ancia_e_tecnologia

\begin{tabular}{l|l|l|l|l|l}
\hline (C) RDBCI: Rev. Digit. Bibliotecon. Cienc. Inf. & Campinas, SP & v.15 & n.2 & p. 508-512 & maio/ago. 2017 \\
\hline
\end{tabular}


incluíram fontes muito específicas ou de interesse restrito a uma área de conhecimento. A análise das fontes terminou em janeiro de 2016, e o objetivo foi incluir, tanto quanto possível, o máximo de documentos relevantes surgidos até essa data. Fontes mais antigas foram incluídas quando consideradas clássicas e úteis para o usuário brasileiro. (CUNHA, 2016, p.xi).

A obra está dividida em três capítulos, a saber: fontes primárias, fontes secundárias e fontes terciárias, além de índice remissivo que facilita a procura da fonte e das referências que foram consultadas para a elaboração da obra.

No primeiro capítulo sobre Fontes primárias, o autor fez um levantamento de 32 tipos de fontes. No segundo capítulo sobre Fontes secundárias, estão elencados 102 tipos, e no último capítulo que trata sobre Fontes terciárias, o autor cunhou incluir 29 tipos de fontes.

É importante salientar, como dito por Caldeira (2001) em relação à primeira edição que "No final da década de 90, a professora Bernadete Santos Campello e outros colaboradores publicaram dois manuais que contextualizaram os diversos tipos de fontes, visando facilitar o ensino e a aprendizagem nessa área, contemplando, respectivamente, as fontes gerais: Formas e expressões do conhecimento, e as especializadas: Fontes de informação para pesquisadores e profissionais", porém não encontramos até o momento obra completa como "Para saber mais: fontes de informação em ciência e tecnologia".

Ainda citando Caldeira (2001) nessa resenha, fazemos um relacionamento das duas edições, sendo que a primeira edição inclui fontes relacionadas, a maioria delas do final da década de noventa e, algumas, já no início do ano 2000, mostrando a intenção do autor em exemplificar a tipologia dos materiais com obras brasileiras e estrangeiras recentes, datadas daquela época (2001). Na segunda edição a atualização acontece a partir de 2001 até janeiro de 2016.

Caldeira (2001) observou na primeira edição que atualidade das fontes, dentre os dicionários e enciclopédias publicados no Brasil, dezesseis são anteriores a 1990. Assim, ele afirmou que esse fato revela "que as fontes de informação brasileiras estão envelhecendo, não havendo esforço dos editores em lançar novas obras ou edições, exceção para os dicionários de língua portuguesa, publicados com grandes tiragens. Mesmo considerando-se que as obras de referência se adequam bem ao formato eletrônico, ainda assim há necessidade de se elaborarem novas obras ou se proceder à atualização das antigas, seja no formato impresso ou em outro suporte."

$\mathrm{Na}$ introdução da obra, o autor deixa uma informação importante aos leitores que "tanto quanto possível, foram incluídos os endereços eletrônicos na internet, que foram conferidos antes de a obra ir para o prelo. Entretanto, tendo em vista a volatilidade desses endereços, é provável que alguns não estejam funcionando e/ou hajam sido transferidos para

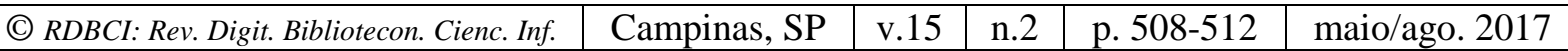


outros sítios. Em razão disso, o autor, de forma antecipada, solicita a colaboração dos leitores para a correção das mudanças que forem detectadas.” (p.xii)

Por fim, essa nova edição da obra "Para saber mais: fontes de informação em ciência e tecnologia", do meu ponto de vista não é direcionada apenas para bibliotecários e alunos de Biblioteconomia. Ela permite também ser muito útil para usuários dos diversos campos do conhecimento, bem como alunos, pesquisadores e estudiosos que precisam conhecer, ou melhor, "saber", como o próprio título induz, a utilizar as inúmeras fontes aqui citadas tanto no contexto nacional como internacional.

\section{REFERÊNCIAS}

CALDEIRA, Paulo da Terra. Resenha: CUNHA, Murilo Bastos da. Para saber mais: fontes de informação em ciência e tecnologia. Brasília: Briquet de Lemos/Livros, 2001. 168p. In: PERSPECTIVAS EM CIÊNCIA DA INFORMAÇÃO, Belo Horizonte, v.6, n.2, 2001. ISSN 1981-5344.

CUNHA, Murilo Bastos da. Para saber mais: fontes de informação em ciência e tecnologia. 2.ed. Brasília, DF: Briquet de Lemos, 2016. 235p. ISBN 858563717X (broch.).
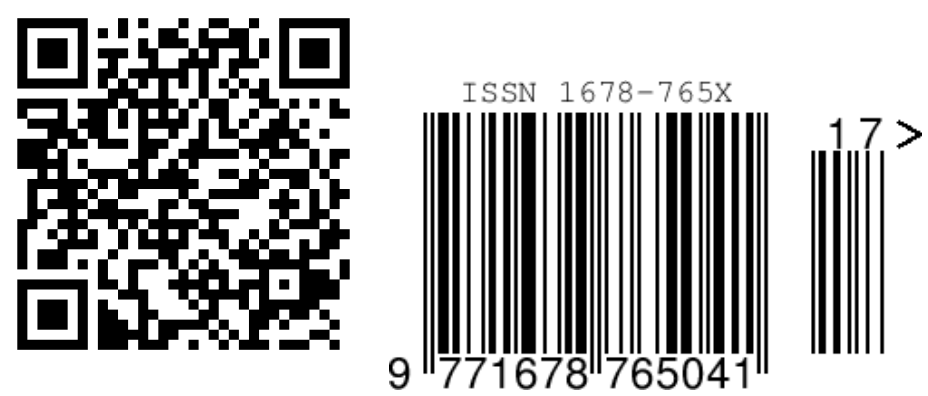